\title{
LC/MS Label-Free Quantification
}

National Cancer Institute

\section{Source}

National Cancer Institute. LC/MS Label-Free Quantification. NCI Thesaurus. Code C161813.

A proteomic quantitation method where a sample is subjected to liquid chromatog raphy mass spectrometry (LC/MS) quantification applications in the absence of tracer molecules. 